\title{
RADIOLYSIS OF TROPANE ALKALOIDS IN AQUEOUS
}

\section{SOLUTIONS}

B. A. Chakchir, S. A. Grachev, and L. D. Ryabykh

UDC 541.15:615.784

Reports on the radiolytic decomposition of the tropane alkaloids are mainly of a preliminary nature [1]. In the present paper we describe the results of a study of the influence of radiation on dilute aqueous solutions of atropine sulfate and scopolamine hydrobromide $(0.0365 \mathrm{M})$ in relation to hydrochloric acid. The source of ionizing radiation was a $\gamma$-irradiating apparatus (with a radioactivity of the ${ }^{60} \mathrm{Co}$ cobalt source of about $30 \mathrm{~kg}-\mathrm{eq}$ of radium). The dose rate determined by a Fricke dosimeter was $266 \pm 3 \mathrm{rad} / \mathrm{sec}$.

The best separation of the alkaloids from the products of their radiolysis was achieved by paper chromatography in the n-butanol-acetic acid-water $(4: 1: 5)$ system. Quantitative chromatographic analysis based on the use of this system [2] permitted the determination of the radiochemical yields of the decomposition of the alkaloids. The value of $G(-M)$ for atropine depended little on the concentration of the solution irradiated. For example, at an absorbed dose of $347,700 \mathrm{rad}$, the yield of the decomposition of atropine in $1.44 \cdot 10^{-3}, 3.60 \cdot 10^{-3}, 7.20 \cdot 10^{-3}$ and $1.44 \cdot 10^{-2}$ solutions was $1.28,1.32,1.36$, and 1.40 molecules/ $100 \mathrm{eV}$, respectively. When the dose was increased in the range between 347,700 and $2,399,900 \mathrm{rad}$, the yield fell from 1.28 to 0.43 molecules $/ 100 \mathrm{eV}\left(1.44 \cdot 10^{-3} \mathrm{M}\right.$ solution). Similar results were obtained in a study of the radiolysis of scopolamine. The decomposition yields at doses of $347,700,1,031,600,1,716,000$, and 2,058,100 rad for a $1.30 \cdot 10^{-3} \mathrm{M}$ solution were $1.67,0.94,0.67$, and 0.51 molecules $/ 100 \mathrm{eV}$, respectively. A reduction in concentration in the range between $1.30 \cdot 10^{-2}$ and $1.30 \cdot 10^{-3} \mathrm{M}$ led to a decrease in $\mathrm{G}(-\mathrm{M})$ from 2.82 to 1.67 molecules $/ 100 \mathrm{eV}$ (at a dose of $347,700 \mathrm{rad}$ ).

A study of the antagonism of native and irradiated solutions of the alkaloids to the myotonic action of acetylcholine performed by the classical Magnus method on isolated rabbit duodenum showed that the biological activity of the preparations fell as radiolytic decomposition took place. Consequently, the products of the radiolysis of atropine and scopolamine are biologically inactive. By using different "markers," tropine and tropic acid were identified among the products of the radiolysis of atropine by paper chromatography. This shows the radiation-induced cleavage of the molecule. Information on the determination of irradiated solutions of esters [3] shows that, in addition to the cleavage of the ester bond, reactions take place which do not lead to the degradation of the molecule and apparently consist in a change both in the acid and the alcohol moiety of the ester (formation of apoatropine, noratropine, etc.). Similar transformations were also observed in the action of radiation on scopolamine.

\section{LITERATURE CITED}

1. E. Pandula and S. Farcas, Acta Pharm. Hung., 37, 78 (1967); E. Pandula, Honvedrvos, 19, 404 (1967).

2. I. A. Barene and S. A. Minina, Rast. Res., 7,124 (1971).

3. Yu. I. Zelikson, Farmatsiya, $\underline{1969}$, No. 2, $\overline{39}$.

S. M. Kirov Academy of Military Medicine. Leningrad Institute of Nuclear Physics, Academy of Sciences of the USSR. Translated from Khimiya Prirodnykh Soedinenii, No. 3, p. 401, May-June, 1972. Original article submitted January 25, 1972.

- 1974 Consultants Bureau, a division of Plenum Publishing Corporation, 227 West I7th Street, New York, N. Y. 10011. No part of this publication may be reproduced, stored in a retrieval system, or transmitted, in any form or by any means, electronic, mechanical, photocopying, microfilming, recording or otherwise, without written permission of the publisher. 1 copy of this article is available from the publisher for $\$ 15.00$. 